\title{
Utility of reverse transcriptase PCR and DNA-PCR in the diagnosis of female genital tuberculosis
}

\author{
Correspondence \\ Urvashi B. Singh \\ drurvashi@gmail.com
}

Received 12 August 2010

Accepted 23 December 2010

\author{
Tanu Rana, ${ }^{1}$ Urvashi B. Singh, ${ }^{1}$ Vidushi Kulshrestha, ${ }^{2}$ Amit Kaushik, ${ }^{1}$ \\ Chhavi Porwal, ${ }^{1}$ Nutan Agarwal $^{2}$ and Alka Kriplani ${ }^{2}$ \\ ${ }^{1}$ Department of Microbiology, All India Institute of Medical Sciences, New Delhi 110029, India \\ ${ }^{2}$ Department of Obstetrics and Gynecology, All India Institute of Medical Sciences, \\ New Delhi 110029, India
}

\begin{abstract}
This study was designed to test the utility of mRNA-based RT-PCR to detect viable bacilli, indicating active tubercular involvement, and DNA-PCR to detect present or past infection in the diagnosis of active female genital tuberculosis (TB) infection. A total of 200 subjects with complaints of infertility were enrolled in the study. Multiple sampling was done. One hundred and forty-three endometrial aspirate (EA), 94 peritoneal fluid/peritoneal washing (PF/PW) and six cornual biopsy (CB) specimens were collected for diagnosis using microscopy, culture, RT-PCR and DNA-PCR and results were compared with laparoscopic findings. RT-PCR and culture were concordant [positive in four (2.8\%) EA specimens] signalling sampling from the site of active infection. Smear microscopy showed a poor detection rate while DNA-PCR showed high positivity. Sixty-one (44.85\%) EA specimens, nine (9.57\%) PF/PW specimens and two (33.33\%) CB specimens were positive by DNA-PCR. Genital TB causing infertility (localized or secondary to TB elsewhere) can be picked up early by DNA-PCR, when it can be completely cured prior to the appearance of florid disease.
\end{abstract}

\section{INTRODUCTION}

One-third of the world's population is infected with Mycobacterium tuberculosis, the aetiological agent of tuberculosis (TB). Female genital TB is a form of extrapulmonary TB affecting the female genital organs, with Fallopian tubes being affected most commonly (90\%), followed by the endometrium (50\%) and the ovaries (10-30\%) (Schaefer, 1976; Sutherland, 1983; Varma, 1991). It is almost always secondary to a tubercular lesion elsewhere in the body. The exact incidence of the disease remains unknown, as the majority of the cases remain undiagnosed due to asymptomatic presentation of genital TB and paucity of investigations. However, the incidence is estimated to range from $<1 \%$ in Western countries to $15-19 \%$ in some African and Asian countries (Punnonen et al., 1983; Giannacopoulos et al., 1998). Early diagnosis of TB is still based on the demonstration of acid-fast bacilli by microscopy and/or their isolation by culture. Microscopy is a poorly sensitive technique (requires $10^{4}$ bacilli $\mathrm{ml}^{-1}$ ) for the diagnosis of TB. Culture has been the gold standard, but the long incubation time often causes delay in diagnosis and treatment. Histopathological examination has also been reported to be of limited use in diagnosis of TB infection

Abbreviations: ATT, anti-TB treatment; CB, cornual biopsy; EA, endometrial aspirate; PF/PW, peritoneal fluid/peritoneal washing; TB, tuberculosis.
(Chakrabarti et al., 1998). PCR-based methods that amplify M. tuberculosis DNA have proven to be very useful for rapid diagnosis of infection in pulmonary as well as extrapulmonary samples (Kolk et al., 1992; Dar et al., 1998; Bhanu et al., 2005). DNA-PCR is unable to differentiate between viable and nonviable organisms while bacterial mRNA with a mean half-life of 3-5 min (Alberts et al., 1989) is more prone to destruction than genomic DNA, hence a positive mRNA signal would indicate the presence of viable organisms (Jou et al., 1997; Desjardin et al., 1999; Hellyer et al., 1999).

In the present study, we evaluated the use of mRNA-based RT-PCR and DNA-PCR in endometrial aspirate (EA), peritoneal washing/peritoneal fluid (PW/PF) and cornual biopsy (CB; biopsy taken from the cornual region) specimens collected from subjects with complaints of infertility.

\section{METHODS}

Patients and samples. The study was conducted after obtaining ethical clearance from the Institute's Ethics Committee. A total of 200 subjects (women) presenting to the Infertility Clinic, Gynecology and Obstetrics Out Patient Department (OPD) of the All India Institute of Medical Sciences (AIIMS), New Delhi, between January 2006 and January 2008 were enrolled in the study after obtaining informed consent. Baseline data of the subjects, viz. age, socio-economic status, prior history of $\mathrm{TB}$, contact history of $\mathrm{TB}$ and chest radiological findings, were collected. Endometrial aspiration and laparoscopy were 
conducted on all patients as part of the workup. Multiple sampling was done whenever possible and $143 \mathrm{EA}, 94 \mathrm{PF} / \mathrm{PW}$ and $6 \mathrm{CB}$ specimens were received at the Tuberculosis Laboratory, Department of Microbiology, AIIMS, for investigation. All the samples were subjected to histopathology, smear for acid-fast bacilli, culture by BACTEC 460 and on Löwenstein-Jensen (LJ) slants, DNA-PCR and mRNA RT-PCR. However, the laboratory was kept blinded to the patient details until all laboratory test results were available.

Sample processing. The specimens were processed following the protocol suggested by Desjardin et al. (1996). Briefly, specimens were homogenized by vortexing after addition of $2.5 \% \mathrm{~N}$-acetyl-L-cysteine (Sigma Chemical) solution in phosphate buffer ( $\mathrm{pH}$ 6.7). The addition of $\mathrm{NaOH}$ was deliberately avoided during decontamination of the specimen as it has been reported to adversely affect the stability of mycobacterial mRNA. The decontaminated specimens were stored frozen at $-80{ }^{\circ} \mathrm{C}$ until further use.

Smear and culture. Smears were made from the decontaminated specimen, heat-fixed and stained using the Ziehl- Neelsen technique and quantified in accordance with the published standards (Kent \& Kubica, 1985). An aliquot of processed sample was cultured on the LJ slants and incubated at $37{ }^{\circ} \mathrm{C}$ for up to 8 weeks. The slants were examined and aerated every week for growth. Another $0.5 \mathrm{ml}$ aliquot was cultured using the BACTEC 460 TB detection system (Becton Dickinson) as per the manufacturer's guidelines.

RNA and DNA isolation. RNA was extracted as per the protocol published by Jou et al. (1997) with certain modifications. The processed specimen was centrifuged at $3000 \mathrm{~g}$ for $10 \mathrm{~min}$, washed and resuspended in $250 \mu \mathrm{l}$ diethyl pyrocarbonate-treated water. The pellet was freeze-thawed $\left(-70{ }^{\circ} \mathrm{C} \leftrightarrow 37^{\circ} \mathrm{C}\right)$ three times to aid cell disruption. Lysis of mycobacteria was carried out further enzymically, first by lysozyme $\left(10 \mathrm{mg} \mathrm{ml}^{-1}\right)$ for $30 \mathrm{~min}$ on ice followed by $5 \mu \mathrm{l}$ $10 \mathrm{mg}$ proteinase $\mathrm{K} \mathrm{ml}^{-1}$. RNA in the lysate was isolated using TRIzol LS reagent (Invitrogen Life Technologies) as per the manufacturer's instructions. To rule out any contaminating DNA, the RNA was treated with RNase-free DNase I (New England Biolabs). The $A_{260} /$ $A_{280}$ ratio was checked to test the purity of extracted RNA.

DNA was extracted using the QIAamp DNA extraction kit (Qiagen) as per the manufacturer's instructions after lysis of the concentrated sediment (Bhanu et al., 2005).

Reverse transcriptase PCR. cDNA was synthesized in a $25 \mu \mathrm{l}$ reaction mixture using a High Efficiency cDNA Archive kit (Applied Biosystems). cDNA was stored at $-20{ }^{\circ} \mathrm{C}$ for PCR amplification. Following reverse transcription, amplification was performed in a nested manner using primers described by Jou et al. (1997). Two rounds of amplification were carried out using $20 \mathrm{pmol}$ of the outer primers and $25 \mathrm{pmol}$ of the inner primers. The first amplification included 30 cycles of denaturation at $94{ }^{\circ} \mathrm{C}$ for $1 \mathrm{~min}$, annealing and extension at $70{ }^{\circ} \mathrm{C}$ for $1.5 \mathrm{~min}$ and final extension at $70{ }^{\circ} \mathrm{C}$ for $7 \mathrm{~min}$. The cycling for the second amplification was: initial denaturation at $94{ }^{\circ} \mathrm{C}$ for $5 \mathrm{~min}$; 30 cycles of denaturation at $94{ }^{\circ} \mathrm{C}$ for $45 \mathrm{~s}$, annealing at $60{ }^{\circ} \mathrm{C}$ and extension at $72{ }^{\circ} \mathrm{C}$ for $50 \mathrm{~s}$ and final extension for $10 \mathrm{~min}$ at $72{ }^{\circ} \mathrm{C}$. The amplification of the Ag85B target was checked by electrophoresis on a $1.5 \%$ agarose gel. Using a Gel Documentation System (ChemiImager; Alpha Innotech), amplified products having a $216 \mathrm{bp}$ band were identified as positive. To rule out contamination, various controls (one negative extraction control per three specimens, minus reverse-transcriptase control and several negative PCR amplification controls) were used. Additionally, the inhibitions were checked by using spiked controls.

DNA-PCR. A 240 bp region of the mpt64 gene of M. tuberculosis was amplified using the protocol described previously (Bhanu et al., 2005). Appropriate positive and negative controls were included in each run.

Analysis of results. The patients were classified according to the laparoscopic findings into five groups as listed in Table 1. The classification used was a modification of the classification used in a previous study (Bhanu et al., 2005).

Patient control group. EA and PF/PW specimens were collected from 55 subjects (controls) with normal laparoscopy and diagnoses other than TB to rule out the possibility of picking up false-positive results. The specimens were processed similarly to the suspected diseased specimens and smear microscopy, culture, RT-PCR and DNA-PCR were performed.

\section{RESULTS}

A total of 200 subjects were enrolled in the study; 143 were evaluable upon the completion of study. Subjects were withdrawn from the study if they conceived postendometrial aspiration, if the cause of infertility was involvement of a male factor, if the RT-PCR could not be done or if the subject was lost to follow-up. In all, 143 $\mathrm{EA}, 94 \mathrm{PF} / \mathrm{PW}$ and $6 \mathrm{CB}$ specimens were taken.

\section{Smear microscopy}

Three $(2.09 \%)$ EA specimens were positive by microscopy and all with scanty bacilli (one to nine bacilli per 100 oil fields). Laparoscopy was done only in one patient (at the same time as endometrial aspiration and hence before the smear report). In the other two patients, laparoscopy was

Table 1. Classification based on laparoscopic findings

Number of subjects in each category and the nature of the samples.

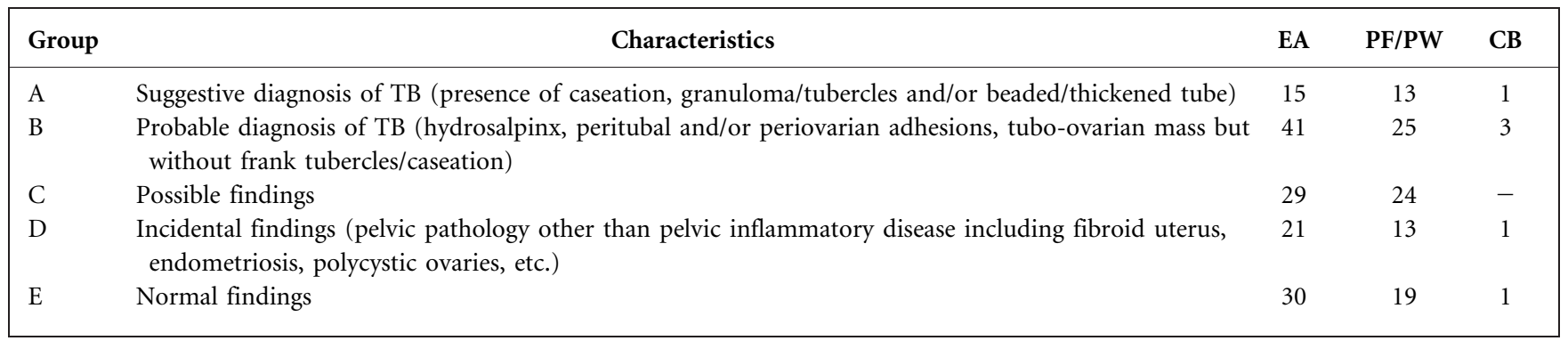


withheld after the smear report for fear of disseminating the disease. The other EA, PF/PW and CB specimens were negative by microscopy.

\section{RT-PCR and culture}

RT-PCR was positive in four $(2.8 \%)$ EA specimens. A repeat RT-PCR confirmed that the results were reproducible. All four RT-PCR-positive EA specimens grew $M$. tuberculosis in BACTEC as well as LJ medium. RT-PCR, BACTEC and LJ cultures were negative for all the other EA, $\mathrm{PF} / \mathrm{PW}$ or $\mathrm{CB}$ specimens.

\section{DNA-PCR}

DNA-PCR showed the highest positivity among the four tests. Sixty-one EA, nine PF/PW and two CB specimens were positive for DNA-PCR. Of the nine subjects with PF/ PW specimens positive for DNA-PCR, seven (77.7\%) had a positive DNA-PCR for EA as well. Two subjects with $\mathrm{CB}$ positive for DNA-PCR had positive DNA-PCR for EA also; PF/PW DNA-PCR in these subjects was negative.

\section{Laparoscopy}

The subjects were classified according to the laparoscopic findings into five groups. The number of patients in each category, the nature of the samples used and the test results are given in Tables 1 and 2.

\section{Clinical history}

The laboratory was blinded to the clinical history of all the subjects in the study (including the patients taken as controls). The subjects were grouped on the basis of laparoscopic findings. These data were revealed only after the completion of laboratory tests. Out of 143 subjects, 101 $(70.6 \%)$ patients had primary infertility and $42(29.3 \%)$ had secondary infertility. All the subjects belonged to the reproductive age group and were between 20 and 38 years of age with mean age being 27.8 years (SD 4.00, median 27). Forty-two subjects $(29.3 \%)$ had a prior history of TB [8 pulmonary, 34 extrapulmonary (9 infertility)] and all of them had received anti-TB treatment (ATT).
Chest radiography (posteroanterior view) was done for all the subjects. The findings were normal in all patients except three (one with calcified granuloma, one with osteochondroma and one with patchy pneumonitis). The subject with calcified granuloma had a positive DNA-PCR for EA. The subject with an osteochondroma had an EA specimen positive for RT-PCR, culture and DNA-PCR and a PF/PW specimen positive for DNA-PCR. Finally, the subject with patchy pneumonitis had an EA specimen positive for RT-PCR, culture and DNA-PCR. However, by laparoscopy only the subject with patchy pneumonitis showed evidence suggestive of TB (group A).

\section{Histopathology}

Histopathology could only be done for 98 EA specimens. Only four $(4 / 98 ; 4 \%)$ specimens showed the presence of granuloma, of which one had necrotizing granuloma and one had necrotizing epitheloid cell granuloma. Only the patient with necrotizing granuloma had a positive DNAPCR for EA while the specimens collected from the other three subjects with granulomas were found to be negative for all four laboratory tests.

\section{Patient control group}

None of the specimens collected from control group subjects tested positive for smear microscopy, culture and RT-PCR. However, five EA specimens showed a positive DNA-PCR.

\section{ATT}

ATT was initiated using first-line treatment with isoniazid, rifampicin, pyrazinamide and ethambutol for 2 months followed by isoniazid and rifampicin for the next 4 months. In all, 91/143 (63.63\%) subjects were given ATT. All subjects in group A (15) and 35 subjects in group B were given ATT irrespective of the laboratory test results. Three of the subjects in group B had just finished taking ATT when they came to the clinic, while three others were advised ATT but were lost to follow-up. Subjects in group $\mathrm{C}$, group D and group E were administered ATT only if they had a positive smear, culture, DNA-PCR or RT-PCR.

Table 2. Number of samples in each category positive for the smear microscopy, culture, RT-PCR and DNA-PCR

\begin{tabular}{|c|c|c|c|c|c|c|c|c|c|c|c|c|}
\hline \multirow[t]{2}{*}{ Group } & \multicolumn{4}{|c|}{ EA } & \multicolumn{4}{|c|}{$\mathrm{PF} / \mathrm{PW}$} & \multicolumn{4}{|c|}{$\mathrm{CB}$} \\
\hline & Smear & Culture & RT-PCR & DNA-PCR & Smear & Culture & RT-PCR & DNA-PCR & Smear & Culture & RT-PCR & DNA-PCR \\
\hline A (15) & - & - & - & 8 & - & - & - & 1 & - & - & - & - \\
\hline B (41) & - & 3 & 3 & 19 & - & - & - & 1 & - & - & - & 1 \\
\hline C (29) & - & 1 & 1 & 8 & - & - & - & 4 & - & - & - & - \\
\hline $\mathrm{D}(21)$ & - & - & - & 9 & - & - & - & - & - & - & - & 1 \\
\hline E (30) & 1 & - & - & 17 & - & - & - & 3 & - & - & - & - \\
\hline
\end{tabular}


Twelve subjects in group C, seven patients in group D and 16 patients in group E were given ATT.

\section{Outcome}

Fourteen $(14 / 91 ; 15.38 \%)$ subjects conceived post ATT. These included two patients from group $\mathrm{A}$, one with a positive DNA-PCR for EA; four patients from group B, two with a positive DNA-PCR for EA and one with positive RT-PCR, culture and DNA-PCR for EA; six patients from group E, four with a positive DNA-PCR for EA, one with a positive DNA-PCR for EA and PF/PW and one with a positive smear for EA.

\section{DISCUSSION}

Female genital TB is a major health problem, especially in developing countries. A few publications have shown TB to be responsible for approximately $5-16 \%$ of cases of infertility among Indian women (Roy et al., 1993; Krishna et al., 1979; Parikh et al., 1997). Singh et al. (2008) concluded that $48.5 \%$ of patients with tubal factor infertility had TB. Diagnosis of genital tract TB has profound implications for asymptomatic women seeking fertility. The diagnostic dilemma arises because of varied clinical presentations, diverse results on imaging and laparoscopy and availability of a battery of bacteriological, serological, histopathological and molecular tests which are often required to obtain collective evidence for the diagnosis and may still be inconclusive.

The RT-PCR assay was performed to illustrate its use as a sensitive marker of viability in gynaecological specimens, the disease being paucibacillary. RT-PCR and culture (BACTEC) showed complete $(100 \%)$ concordance and were positive in four $(2.8 \%)$ EA specimens. This indicates that mRNA-based RT-PCR was able to detect active infection in these subjects. These samples hence were the only samples with live bacilli. Nevertheless, the test is rapid though labour-intensive and could be used to save time to diagnosis and as definite evidence of activity in place of culture.

DNA-PCR showed high positivity among the four laboratory tests, ranging from $9.57 \%$ in $\mathrm{PF} / \mathrm{PW}$ specimens to $44.85 \%$ in EA specimens. Previous studies (Bhanu et al., 2005; Krishna et al., 1979; Parikh et al., 1997; Jindal, 2006; Gupta et al., 2007; Sharma et al., 2008; Abebe et al., 2004) have also documented high positivity for DNA-PCR performed on EA specimens, varying from $22.5 \%$ to $64.7 \%$. DNA-PCR targeting the mpt64 gene used in the study is an in-house PCR, having been used in our laboratory for diagnostic purposes for over 15 years. The PCR has been demonstrated to have a high sensitivity and specificity (Singh et al., 2006; Seth et al., 1996). Several concurrent negative controls are used during sample handling, DNA extraction and PCR, with due care in separate rooms, in order to rule out the possibility of contamination/false-positive results.
Seven subjects had positive DNA-PCR for both EA and PF/ PW specimens and two had positive DNA-PCR for both EA and $\mathrm{CB}$ specimens. However, two subjects had a positive DNA-PCR for PF/PW specimens only. These two subjects $(1.3 \%)$ could have been missed if EA specimens alone had been used for diagnosis hence implying that use of multiple sampling sites significantly improves the diagnostic yield. It is possible that these subjects may have had the onset of the disease in the tube without the endometrium being involved yet. PCR positivity in peritoneal fluid may be indicative of bacillary spillover into the peritoneum, probably early in the disease, before fibrosis sets in.

The DNA-PCR test, being highly sensitive (three to five bacilli) and specific, is often questioned for comparison with a gold standard diagnostic modality for female genital TB. In the absence of a more sensitive laboratory gold standard, clinical findings including the laparoscopic findings have been put to use for evaluation.

Gynaecological TB is almost always secondary to a primary focus elsewhere in the body. The chest radiograph was done to rule out primary pulmonary focus. Three patients showed distinct findings, one with calcified granuloma, one with osteochondroma and one with patchy pneumonitis. The subject with calcified granuloma had a positive DNAPCR for the EA specimen. The subject with an osteochondroma had an EA specimen positive for RT-PCR, culture and DNA-PCR and a PF/PW specimen positive for DNAPCR. The subject with patchy pneumonitis had an EA specimen positive for RT-PCR, culture and DNA-PCR. The latter two showed clear evidence of active disease in the genital samples along with the involvement of the lung/ osteochondral tissue. The subject with patchy pneumonitis showed features suggestive of TB (group A) by laparoscopy as well. The first patient is a good example of dormant/ healed disease in the lung with a DNA-PCR-positive result in the EA sample, hence giving credence to the strength of the DNA-PCR test to pick up circulating DNA in the body.

The debate that the test can be non-specific and can give false-positives often bothers clinicians. In a quality-assured laboratory set-up, the DNA-PCR test is reliable, though in the absence of activity at the site of sample collection, activity/past disease/latent disease must be looked for elsewhere in the body. All these findings give enough evidence for the utility of DNA-PCR in the detection of early genital tubercular involvement (secondary to primary tubercular involvement elsewhere in the body) prior to the appearance of active disease in the endometrium. Careful examination of the chest X-ray and other radiological evidence of disease activity elsewhere may help reach the primary site of disease in some of the patients with secondary involvement of the genital tract. However, negative findings cannot rule out the possibility of genital disease.

Detection of quiescent or early disease by PCR in group E could explain the positivity in this group. Dam et al. (2006) have also concluded that latent TB should be considered in 
young Indian patients presenting with unexplained infertility with apparently normal pelvic and non-endometrial tubal factors and repeated in vitro fertilization failure.

Laparoscopy detects only macroscopic changes such as peritubal adhesions, tubercles on the tubes and small tuboovarian masses that are commonly seen in chronic cases. Genital TB presents unique diagnostic challenges including subtle clinical manifestations that may be overlooked in laparoscopy during early stages of infection. It is here that the molecular laboratory tests, especially PCR-based assays with their higher sensitivities, aid the diagnosis of infection.

Based on the collective evidence gathered from laparoscopy, clinical features and laboratory test results, 91 subjects were administered ATT. Fourteen (14/91; $15.38 \%$ ) subjects conceived post ATT. This included six subjects from group E (normal findings). The results are significantly better than those in other studies where poor outcome has been reported in subjects with genital TB. Saracoglu et al. (1992) and Jindal (2006) have reported conception in $2.9 \%$ and $4.3 \%$ of subjects with genital TB.

Female genital TB is more often a silent disease. Patients may present with non-specific complaints of pelvic pain, menstrual irregularities or infertility, irrespective of the severity or time since disease. The evidence in the form of any of the investigations may hence be treated as nonspecific if the clinical evidence is not supportive of advanced disease. As has been shown, the laparoscopic findings, though considered the clinical gold standard for diagnosis, may take a long time to manifest. Hence it may prove useful to give due importance to tests indicative of early onset of tubercular involvement by molecular level detection rather than macroscopic. It would be prudent to treat the patient early rather than wait until tubal blockage or other such irreversible damage sets in for want of laparoscopic evidence.

\section{ACKNOWLEDGEMENTS}

Tanu Rana gratefully acknowledges the research fellowship from the Council of Scientific and Industrial Research, Government of India.

\section{REFERENCES}

Abebe, M., Lakew, M., Kidane, D., Lakew, Z., Kiros, K. \& Harboe, M. (2004). Female genital tuberculosis in Ethiopia. Int J Gynaecol Obstet 84, 241-246.

Alberts, B., Bray, D., Lewis, J., Raff, M., Roberts, K. \& Watson, J. D. (1989). Control of gene expression. In Molecular Biology of the Cell, 2nd edn, p. 595. New York: Garland Publishing.

Bhanu, N. V., Singh, U. B., Chakraborty, M., Suresh, N., Arora, J., Rana, T., Takkar, D. \& Seth, P. (2005). Improved diagnostic value of PCR in the diagnosis of female genital tuberculosis leading to infertility. J Med Microbiol 54, 927-931.

Chakrabarti, A. K., Sen, S., Banerjee, A. \& Roy, K. (1998). Female genital tuberculosis - a retrospective study. Indian J Tuberc 45, 101103.
Dam, P., Shirazee, H. H., Goswami, S. K., Ghosh, S., Ganesh, A., Chaudhury, K. \& Chakravarty, B. (2006). Role of latent genital tuberculosis in repeated IVF failure in the Indian clinical setting. Gynecol Obstet Invest 61, 223-227.

Dar, L., Sharma, S. K., Bhanu, N. V., Broor, S., Chakraborty, M., Pande, J. N. \& Seth, P. (1998). Diagnosis of pulmonary tuberculosis by polymerase chain reaction for MPB64 gene: an evaluation in a blind study. Indian J Chest Dis Allied Sci 40, 5-16.

Desjardin, L. E., Perkins, M. D., Teixeira, L., Cave, M. D. \& Eisenach, K. D. (1996). Alkaline decontamination of sputum specimens adversely affects stability of mycobacterial mRNA. J Clin Microbiol 34, 2435-2439.

Desjardin, L. E., Perkins, M. D., Wolski, K., Haun, S., Teixeira, L., Chen, Y., Johnson, J. L., Ellner, J. J., Dietze, R. \& other authors (1999). Measurement of sputum Mycobacterium tuberculosis messenger RNA as a surrogate for response to chemotherapy. Am J Respir Crit Care Med 160, 203-210.

Giannacopoulos, K. Ch., Hatzidaki, E. G., Papanicolaou, N. C., Relakis, K. J., Kokori, H. G. \& Giannacopoulou, C. C. (1998). Genital tuberculosis in a HIV infected woman: a case report. Eur J Obstet Gynecol Reprod Biol 80, 227-229.

Gupta, N., Sharma, J. B., Mittal, S., Singh, N., Misra, R. \& Kukreja, M. (2007). Genital tuberculosis in Indian infertility patients. Int J Gynaecol Obstet 97, 135-138.

Hellyer, T. J., DesJardin, L. E., Hehman, G. L., Cave, M. D. \& Eisenach, K. D. (1999). Quantitative analysis of mRNA as a marker for viability of Mycobacterium tuberculosis. J Clin Microbiol 37, 290-295.

Jindal, U. N. (2006). An algorithmic approach to female genital tuberculosis causing infertility. Int J Tuberc Lung Dis 10, 1045-1050.

Jou, N. T., Yoshimori, R. B., Mason, G. R., Louie, J. S. \& Liebling, M. R. (1997). Single-tube, nested, reverse transcriptase PCR for detection of viable Mycobacterium tuberculosis. J Clin Microbiol 35, 11611165.

Kent, P. T. \& Kubica, G. P. (1985). Public Health Mycobacteriology: a Guide for the Level III Laboratory, pp. 71-120. Atlanta, GA: Centers for Disease Control and Prevention.

Kolk, A. H. J., Schuitema, A. R. J., Kuijper, S., van Leeuwen, J., Hermans, P. W., van Embden, J. D. \& Hartskeerl, R. A. (1992). Detection of Mycobacterium tuberculosis in clinical samples by using polymerase chain reaction and a nonradioactive detection system. J Clin Microbiol 30, 2567-2575.

Krishna, U. R., Sheth, S. S. \& Motashaw, N. D. (1979). Place of laparoscopy in pelvic inflammatory disease. J Obstet Gynaecol India 29, 505-510.

Parikh, F. R., Nadkarni, S. G., Kamat, S. A., Naik, N., Soonawala, S. B. \& Parikh, R. M. (1997). Genital tuberculosis - a major pelvic factor causing infertility in Indian women. Fertil Steril 67, 497-500.

Punnonen, R., Kiilholma, P. \& Meurman, L. (1983). Female genital tuberculosis and consequent infertility. Int J Fertil 28, 235-238.

Roy, A., Mukherjee, S., Bhattacharya, S., Adhya, S. \& Chakraborty, P. (1993). Tuberculous endometritis in hills of Darjeeling: a clinicopathological and bacteriological study. Indian J Pathol Microbiol 36, 361-369.

Saracoglu, O. F., Mungan, T. \& Tanzer, F. (1992). Pelvic tuberculosis. Int J Gynaecol Obstet 37, 115-120.

Schaefer, G. (1976). Female genital tuberculosis. Clin Obstet Gynecol 19, 223-239.

Seth, P., Ahuja, G. K., Bhanu, N. V., Behari, M., Bhowmik, S., Broor, S., Dar, L. \& Chakraborty, M. (1996). Evaluation of polymerase chain reaction for rapid diagnosis of clinically suspected tuberculous meningitis. Tuber Lung Dis 77, 353-357. 
Sharma, J. B., Roy, K. K., Pushparaj, M., Kumar, S., Malhotra, N. \& Mittal, S. (2008). Laparoscopic findings in female genital tuberculosis. Arch Gynecol Obstet 278, 359-364.

Singh, U. B., Bhanu, N. V., Suresh, V. N., Arora, J., Rana, T. \& Seth, P.

(2006). Utility of polymerase chain reaction in diagnosis of tuberculosis from samples of bone marrow aspirate. Am J Trop Med Hyg 75, 960-963.
Singh, N., Sumana, G. \& Mittal, S. (2008). Genital tuberculosis: a leading cause for infertility in women seeking assisted conception in North India. Arch Gynecol Obstet 278, 325-327.

Sutherland, A. M. (1983). The changing pattern of tuberculosis of the female genital tract. A thirty year survey. Arch Gynecol 234, 95-101.

Varma, T. R. (1991). Genital tuberculosis and subsequent fertility. Int J Gynaecol Obstet 35, 1-11. 